\title{
Short-Timescale Chemo-Mechanical Effects and their Influence on the Transport Properties of Fractured Rock
}

\author{
Derek Elsworth ${ }^{1}$ and Hideaki Yasuhara, ${ }^{1,2}$
}

\begin{abstract}
Anomalous changes in permeability are reported in fractures circulated by fluids undersaturated with respect to the mineral host. Under net dissolution and net removal of mineral mass, fractures may alternately gape or seal, depending on the prevailing mechanical and chemical conditions. The influence on transport properties is observed to be large, rapid, and irreversible: Permeabilities may change by two orders of magnitude in a month, and the direction of permeability change may switch spontaneously, for no apparent change in environmental forcing. These behaviors are apparent in continuous circulation experiments conducted on fractures in novaculite and limestone, intermittently imaged by X-ray CT. In novaculite, permeability reduces by two orders of magnitude as silica is net removed from the sample. Surprisingly, these changes can occur at modest temperatures $\left(\sim 80^{\circ} \mathrm{C}\right)$ and stresses $(\sim 3.5 \mathrm{MPa})$, where compaction progresses as temperatures are incremented. Isothermal $\left(\sim 20^{\circ} \mathrm{C}\right)$ circulation tests in limestone show similar compaction driven by pressure solution. Where circulation remains undersaturated in $\mathrm{Ca}$, the change in permeability spontaneously switches from net reduction to net increase as a wormhole forms. The surprising magnitude and rapidity of these changes are investigated in the context of the competition between stress- and chemistry-mediated effects.
\end{abstract}

Key words: Precipitation, dissolution, permeability, fracture, pressure solution.

\section{Introduction}

The important interaction between mechanically-driven and chemically-driven processes has been recognized in controlling the evolution of the mechanical and transport constitutive relations for fractured rocks. These interactions are especially important in fractured rocks, where both mechanical stiffness and strength, and permeability, are sensitive to small changes in the infilling or erosion of fracture voids, or changes in contact area. Despite this importance, views of these complex processes have grown in two separate communities; One where mechanical effects dominate, and chemical influences are merely overprinted on these mechanical effects; and one where chemical effects dominate, and mechanical influences are merely overprinted on

\footnotetext{
${ }^{1}$ Department of Energy and Geo-Environmental Engineering, Penn State University, University Park, PA 16802-5000, U.S.A. E-mail: elsworth@psu.edu

${ }^{2}$ Now at: Department of Civil and Environmental Engineering, Ehime University, Matsuyama, 7908577, Japan.
} 
these chemical effects. Largely absent have been the roles of mechanically-mediated chemical effects, and their corollary, chemically-mediated mechanical effects.

A limited understanding of mechanisms is available where the full interaction of mechanical and chemical effects is included. The controlling processes and feedbacks apply, in varying degree, to a variety of disciplines, and at a variety of spatial and temporal scales. These include our understanding of diagenetic processes at basin scale, and our design of successful acidizing treatments, geothermal completions, and in situ leaching sweeps, at more modest length scales. They include our understanding of short-term transients, the migration of boiling zones, and the development of caprocks in geothermal reservoirs, and relate to biofouling and clogging in shallow aquifers. They apply to the deposition and concentration of ores, as well as our ability to recover these valuable commodities by solution mining. The processes and feedbacks apparent in these complex systems are wide ranging, and have broad significance. Key issues relate to both the strength and the sense of various feedbacks and their influence on mechanical and transport behavior.

Data on the nature of full coupling between mechanical and chemical effects in rock fractures are sparse, although specific results are available for the behavior of natural and artificial fractures in granite at moderate temperatures $\left(>300^{\circ} \mathrm{C}\right)$ (MoORE et al., 1994), and in volcanic tuff (LIN et al., 1997) and novaculite (PoLAK et al., 2003) at lower temperatures $\left(50^{\circ}-150^{\circ} \mathrm{C}\right)$. Related data are also available for composite aggregates of quartz (EliAS and HAJASH, 1992; YASUHARA et al., 2004), halite (GrATIER, 1993), calcite (ZHANG et al., 1994) and albite (HAJASH et al., 1998), at moderate temperatures $\left(20-120^{\circ} \mathrm{C}\right)$ and the same material suites at elevated temperatures and pressures (e.g., ZOBACK and BYERleE, 1975; SIDDIQI et al., 1997).

Apparent from these experimental data are the competing roles of processes that increase pore or flaw connectivity (NGWENYA et al., 2003), including dilatant shear (ZHANG et al., 1998; ZHANG et al., 1999), microcracking, thermal cracking and focused dissolution (MoK et al., 2002; COLON et al., 2004), and those that destroy or counteract the evolution of pore interconnectivity (AHARONOV et al., 1998; TENTHOREY et al., 1998; MAIN et al., 2000), including shear (ZHU and WONG, 1997) and hydrostatic compaction, fracture healing, dislocation creep, and pressure solution (Bos et al., 2000) prompted by water-film and free-face diffusion (YASUHARA et al., 2004). The sense of permeability change is controlled by the dominant suite of processes; this is in turn largely controlled by the evolving conditions of effective stress, and temperature in the sample, and species concentrations within the effusing fluid.

The more limited studies on fractures (MOORE et al., 1994; LiN et al., 1997; Durham et al., 2001; POLAK et al., 2003) amplify these observations, indicating an increased sensitivity to HMC (hydro-mechanical-chemical) processes, even at temperatures as low as $100^{\circ} \mathrm{C}$, where the mobile phase is silica, and the test duration is of the order of a month (EliAS and HAJASH, 1992; LIN et al., 1997), where permeability may be reduced by a factor of 10,000 times (LIN et al., 1997). Recent experimental results involving the circulation of hydrothermal fluids $\left(20^{\circ} \mathrm{C}-150^{\circ} \mathrm{C}\right)$ 
through a natural fracture in novaculite (POLAK et al., 2003; YASUHARA et al., 2004) have also shown reductions in permeability of over two orders-of-magnitude within the period of one month, and of spontaneous switching between permeability reduction and permeability increase as only temperatures and flow rates were changed. These observations are interpreted to result from the spontaneous switching between a regime in which asperity dissolution by pressure solution is dominant, to one where free-face etching and fracture widening dominates. This enigmatic switching in permeability occurs for only subtle changes in temperatures and flow rates, with all other test conditions constant. For normal loading of a fracture, the contributing processes are ill-defined, and anticipated senses and magnitudes of the effects on permeability remain poorly constrained. For shear loading, comparable characterizations that identify key processes and define the expected sense and magnitude of permeability changes and their evolution in time remain ill-defined for porous rocks (Bos et al., 2000; Evans et al., 1997; BERNABE et al., 2003b) and unavailable for fractures.

In this work we describe these embryonic characterizations of the role of chemomechanical effects on the evolution of fracture transport properties. These characterizations explain the enigmatic observation that fractures gape with net dissolution (Durham et al., 2001; PolaK et al., 2003). Specifically in this work, process-based models are applied to quantify rates of fracture closure observed in prior experimental data where the role of free-face dissolution is shown important (e.g., the experimental results of POLAK et al., 2004).

\section{Experimental Observations}

Flow-through experiments are reported for fractured samples confined within an $\mathrm{X}$-ray transparent cell to evaluate the influence of stress-mediated changes in dissolution and precipitation on the evolution in transport properties. Cylindrical samples containing a single axial fracture are confined within a flexible membrane and end-to-end flow tests completed, as illustrated in Figure 1. Three independent measurements are made to constrain the processes promoting the redistribution of mineral mass within the fracture: hydraulic flux, mineral mass flux, and volumetric imaging by X-ray CT. First, permeability is monitored continuously by prescribing flow rate and by measuring pressure drop across the sample. Effective stresses are retained within a narrow range by controlling the upstream back pressure. This measurement records permeability, and through this defines change in average aperture within the system (PiggotT and Elsworth, 1993). Second, the net efflux of dissolved mineral mass is measured periodically to provide a record of net mass removal, and to correlate this with observed changes in aperture, defined by the flow tests.

Finally, periodic nondestructive imaging by X-ray CT is used to view redistribution of mineral mass within the heated sample, as illustrated in Figure 2. X-ray CT 


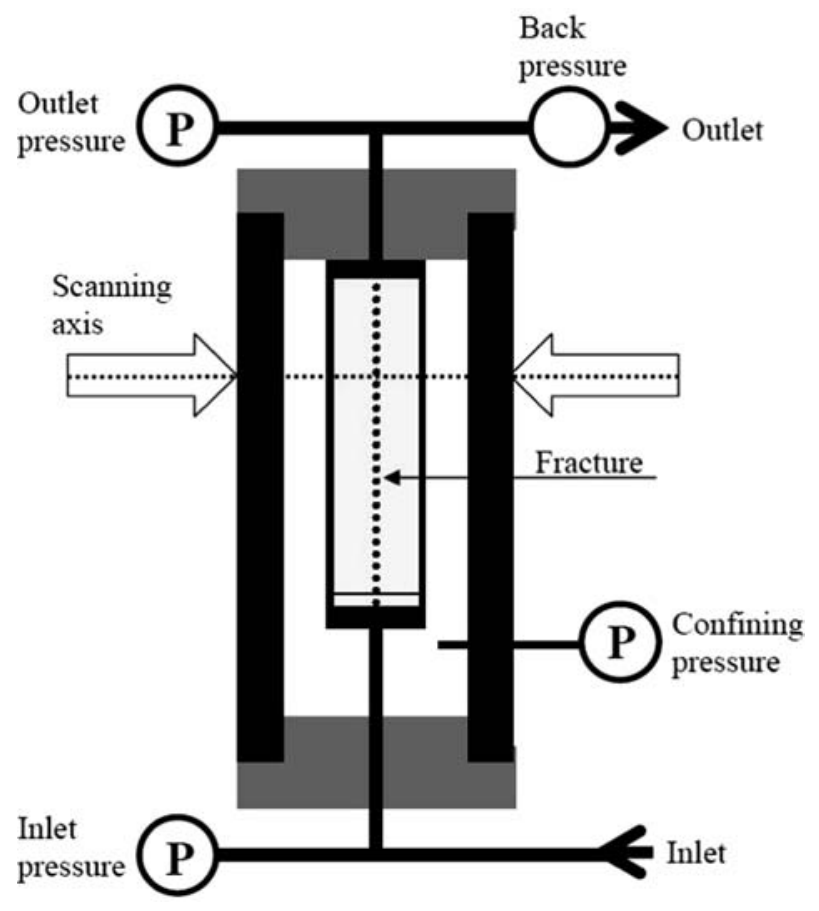

Figure 1

Experimental arrangement showing confining cell and sample with axial fracture. Flow at prescribed flowrate and measured pressure drop records permeability. Constraint on processes is provided by measurement of dissolved mass efflux, and periodic imaging by X-ray CT (POLAK et al., 2003).

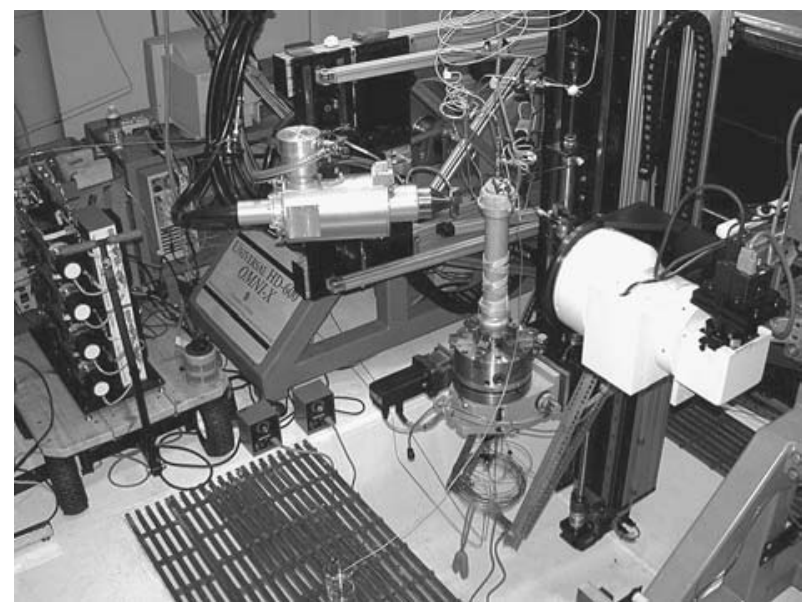

Figure 2

Experimental arrangement showing pressure cell within X-ray CT including plumbing for flow-through tests. Heater tapes provide elevated temperatures to insulated sample. 
records changes in density within the sample as a proxy for mineral removal or redistribution, with the scanner used in this study capable of resolving down to $\sim 1 / 1000$ th of the diameter of the sample. For sample diameters of $3-5 \mathrm{~cm}$ used in the following study, the minimum voxel size scales to the order of $30-50 \mu \mathrm{m}$. This resolution is at the limits of utility in defining mass redistribution.

These measurements provide unusual constraint on the evolving processes. Importantly, they allow the source of dissolved components to be determined: We need to discriminate whether the source is from free-face dissolution of the fracture wall, or from stress-mediated dissolution at contacting asperities. This distinction is crucial since these two mechanisms impart opposite effects in the sense of permeability change, under net dissolution: Free-face dissolution increases permeability, and pressure solution reduces permeability. These behaviors are examined under a uniform framework for novaculite and limestone, where the fundamental material properties control response, as identified in Table 1.

\subsection{Observational Data - Siliceous Rocks}

Constant stress flow-through experiments on a natural fracture in Arkansas Novaculite are reported which observe the bounds of this curious phenomenonwhere net dissolution reduces fracture permeability. Pretest scans of the sample, by X-ray CT with a resolution of $37 \mu \mathrm{m}$, recover an image of the void space present within the fracture, as illustrated in Figure 3. The "islands" of imaged fracture void are presumed connected via open conduits that are less than $37 \mu \mathrm{m}$ in aperture, and are eliminated in the thresholding of the image. This is confirmed by the flow tests, initiated under a confining stress of $3.5 \mathrm{MPa}$ at $20^{\circ} \mathrm{C}$, where the initial mean hydraulic aperture is of the order of $12 \mu \mathrm{m}$, as illustrated in Figure 4. Fluid flow through the sample is at constant rate, $Q$, of $2 \mathrm{cc} / \mathrm{min}$ as the temperature is incremented and held, first to $80^{\circ}$, then to $120^{\circ}$, then to $150^{\circ} \mathrm{C}$. Apparent during heating is the rapid reduction in aperture, and amplified reduction in fracture permeability that accompanies the incremental stages of heating (POLAK et al., 2003). Measured aperture initially drops precipitously, and then slows to an equilibrium

Table 1

Contrasting experimental and material characteristics of the component rock types

\begin{tabular}{ccc}
\hline & Novaculite & Limestone \\
\hline Matrix porosity & $<0.01 \%$ & $<0.01 \%$ \\
Temperature, ${ }^{\circ} \mathrm{C}$ & $2 \mathrm{z} 0-150$ & 20 \\
Effective Stress, $\mathrm{MPa}$ & 3.5 & 3.5 \\
Permeants & $\mathrm{DI}$ & $\mathrm{G} / \mathrm{W} \&$ DI \\
Dissolution rate, Mol.m ${ }^{-2} \cdot \mathrm{s}^{-1}$ & $\sim 10^{-9}$ & $\sim 10^{-6}$ \\
Precipitation rate, Mol.m ${ }^{-2} \cdot \mathrm{s}^{-1}$ & $\sim 10^{-7}$ & \\
\hline
\end{tabular}




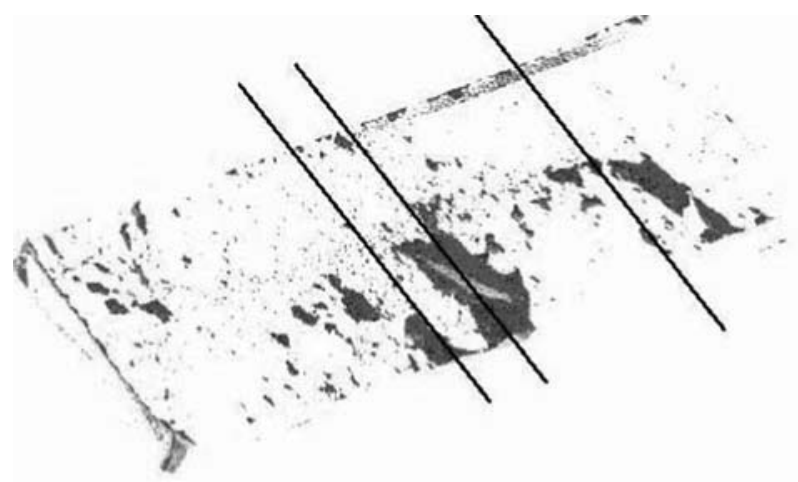

Figure 3

Reconstruction of the fractured sample from X-ray CT imaging [courtesy A.S. Grader].

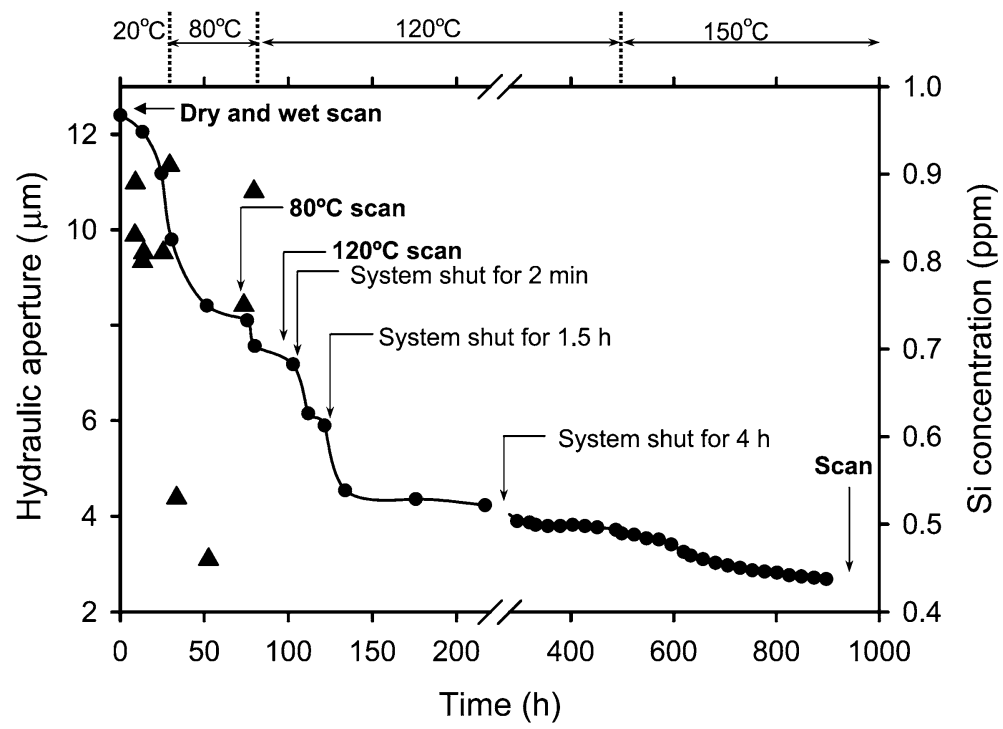

Figure 4

Change in hydraulic aperture with time for a circulation test on a fracture in novaculite. Test is conducted at incremented temperatures but constant stress (POLAK et al., 2003).

magnitude, and occurs with net dissolution of $\mathrm{Si}$ of the order of $0.77 \mathrm{ppm}$ throughout. These changes in fracture aperture are large, reducing aperture five-fold, and permeability by two orders-of-magnitude, and are surprisingly rapid - each thermally driven cycle completes in a few days, and is complete for the full range of temperatures in only 40 days.

Perhaps even more interesting than the large and rapid change in permeability, is the sense of the permeability change-permeability reduces despite net dissolution 
from the fracture. The presumed mechanism for this is through pressure solution at the contacting asperities. Locally amplified stresses at asperity contacts elevate the chemical potential of the silica that, in turn, is mobilized into the saturated fracture void, and removed from the system. The reasonableness of this mechanism may be evaluated by comparing the observed change in fracture aperture, $b$, with the anticipated mass removal rate, $d M / d t$, measured in the experiment. For a defined fracture contact area, $A_{c}$, and density of quartz, $\rho_{g}$, these are linked through the effluent concentration, $C_{p}$, as $d b / d t=d M / d t \cdot 1 / A_{c} \rho_{g}=Q C_{p} / A_{c} \rho_{g}$ (YAsuHARA et al., 2004). For the average effluent concentration of $S i$, of $0.77 \mathrm{ppm}$ and fractional contact areas in the range $5-30 \%$, this results in calculated aperture closure rates of the order of $10^{-10}$ to $10^{-12} \mathrm{~m} / \mathrm{s}$, with measured closure rates, in the range $10^{-11}$ to $10^{-13} \mathrm{~m} / \mathrm{s}$. Correspondingly, removal of mineral mass from the contacting asperities is a plausible explanation for the observed behavior, and is consistent with the
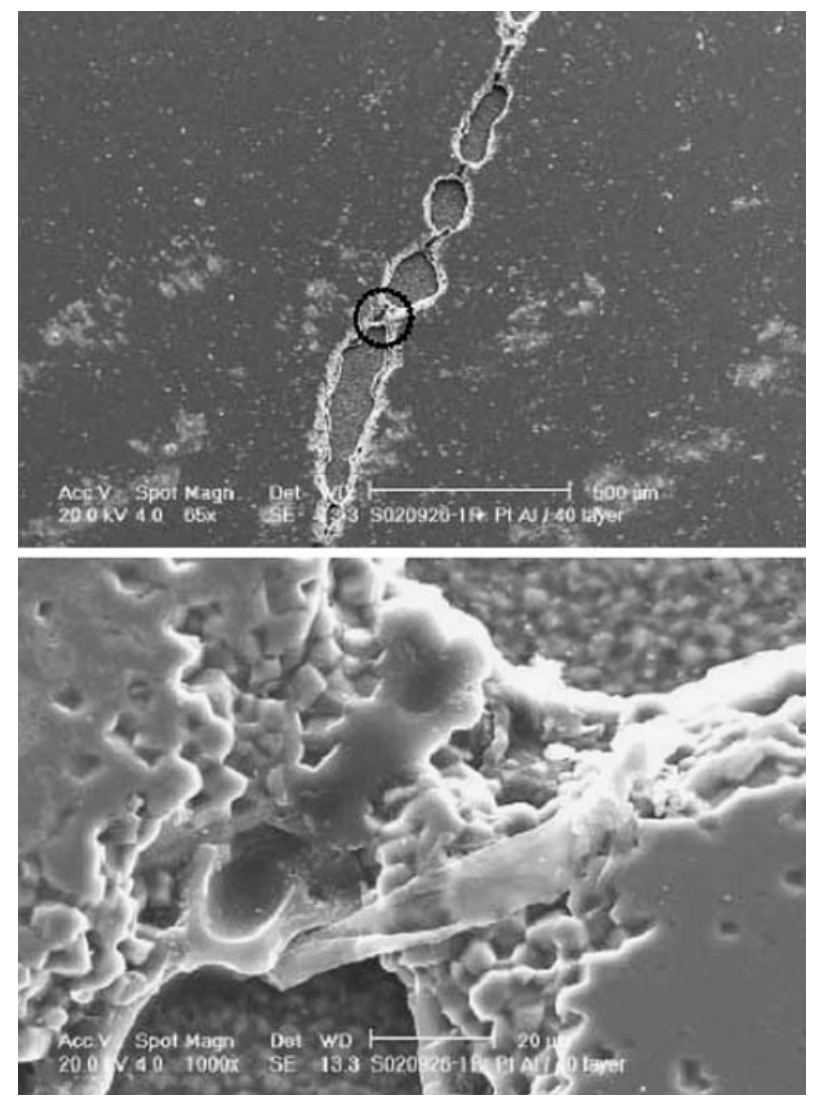

Figure 5

SEM of fracture post test, showing locations of welded fracture [courtesy A.B. Polak]. 
activation of pressure solution. This behavior is also consistent with observations of the sectioned fracture, post-test, where SEM micrographs show dissolution sites, and the blunting and welding of asperity contacts in a natural fracture that had been separated prior to the test (Fig. 5).

The stress-mediated redistribution of mineral mass by pressure solution may be represented by the three serial processes of: mineral dissolution beneath the contacting asperity, transport along an interfacial water-film to the fracture void, and then redistribution by precipitation within the fracture void, or efflux from the sample. The asperities interpenetrate as mass is removed from contacting asperities, in a similar manner to the mechanisms that drive grain interpenetration and cementation in sandstones (YASUHARA et al., 2003).

\subsection{Observational Data-Carbonate Rocks}

Flow through tests on fractured carbonates show similar results - permeability net reduces as mineral mass is net removed. This response is again driven by pressure solution. The net (outlet minus inlet) mineral concentrations within fluids circulated during a flow-though test on a fracture in limestone (POLAK et al., 2004) are shown in Figure 6. Groundwater $(\mathrm{pH} \sim 8)$ is circulated for the initial $935 \mathrm{~h}$, followed by the circulation of distilled water $(\mathrm{pH} \sim 6)$ for the final $515 \mathrm{~h}$. The change in permeability recorded through this period is shown in Figure 7. This notes the steady monotonic decline in permeability that occurs with the circulation of groundwater-the fracture net closes despite a small net dissolution. Following the switching of the permeant to distilled water $(\mathrm{pH} \sim 6)$, the reduction in aperture initially accelerates, driven by the amplification of pressure solution as the dissolution rate constant is elevated in the more acidic permeant. This change is manifest as a coherent signal in the elevated output of $\mathrm{Ca}$, signalling the more active effect of pressure solution. However, following this increase in fracture closure rate, and with no change in the experimental conditions, permeability change spontaneously switches from net reduction to a rapid increase.

The switch in response results from the observed localization of mass dissolution along a narrow conduit, evident in the fracture morphology captured in CT images taken both pre- and post-test (Fig. 8). These images show the localization of mass removal along a "wormhole" that grows and ultimately dominates flow within the system. Since these experiments provide independent constraint on hydraulic behavior and the redistribution of mass within the sample (through measurements of effluent concentrations and through imaging by X-ray CT), these measurements may be compared. If consistency is sought between the observed hydraulic and mineral mass balance data, then added constraint is applied to the problem, as evident in Figure 7.

Anticipated changes in permeability may be predicted from the mass removal rates, provided an appropriate mechanistic model is prescribed. Assuming that 

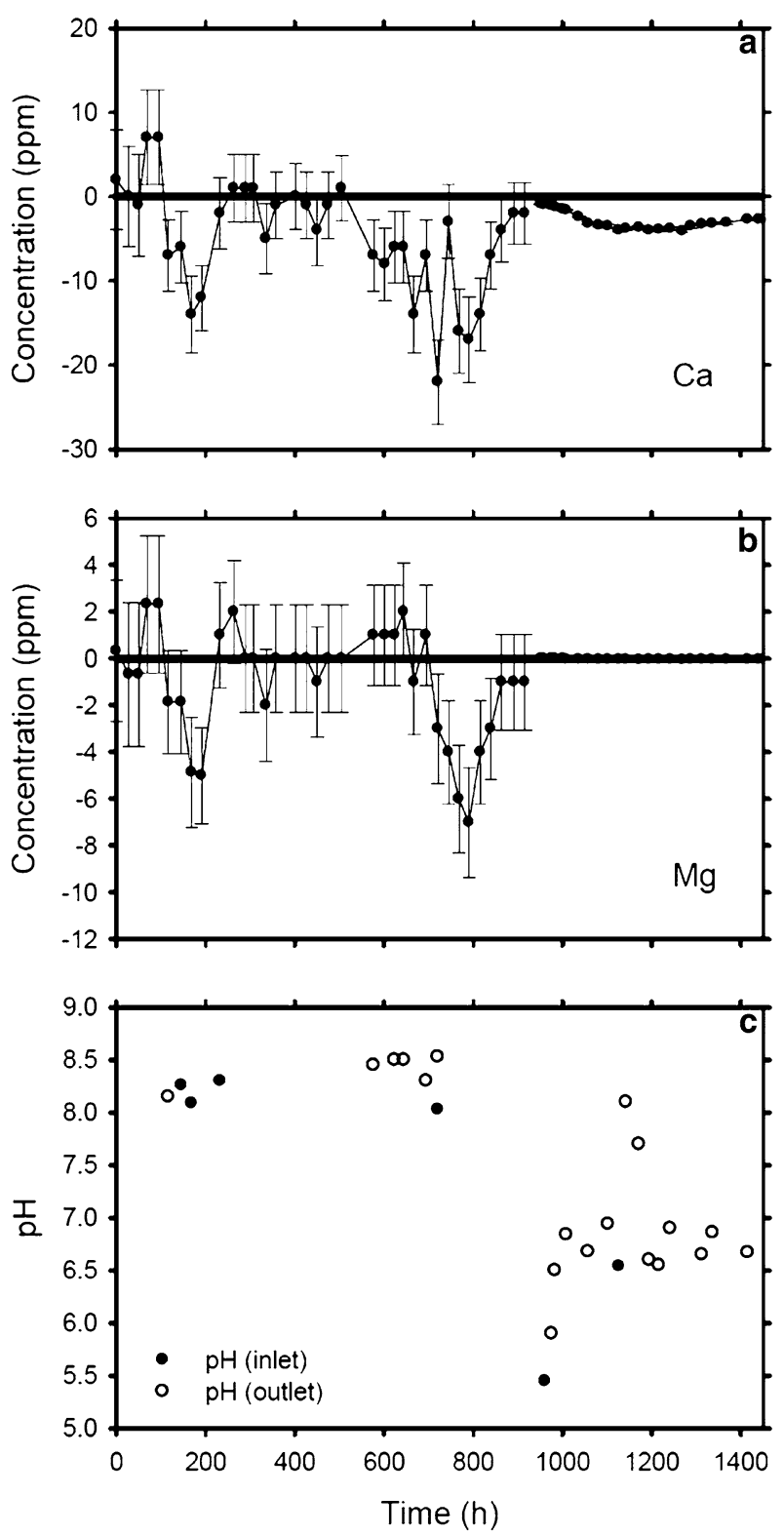

Figure 6

Net efflux in $C a$ and $M g$, and change in $\mathrm{pH}$ with time for the flow-through test on limestone (PoLAK et al., 2004).

mass is removed only from the contacting asperities, and that the contact area is typically in the range $5-30 \%$, then permeability may be evaluated directly. Applying this procedure to the data in Figure 7, shows the difficulty in balancing 

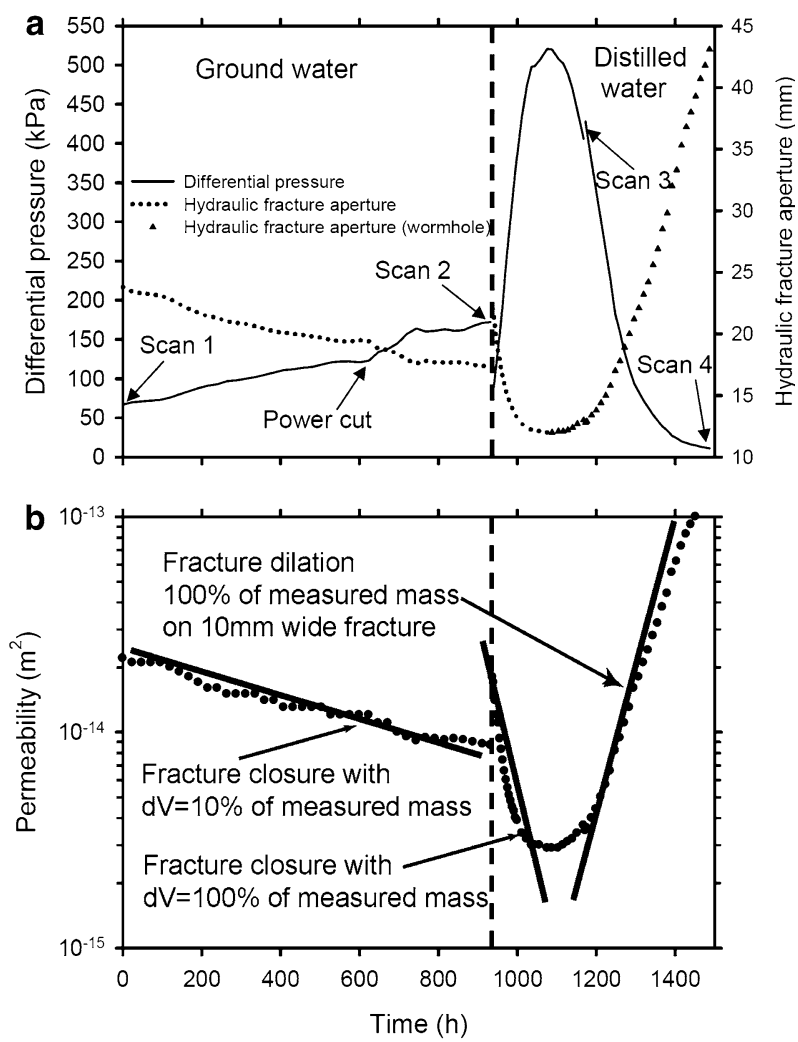

Figure 7

Change in (a) driving differential pressure with time, and for aperture change with time, for flow-through test.

(b) Change in permeability with time, evaluated from the flow data (Modified from POLAK et al., 2004).

measured mass removed with that observed in early time - the measured mass removed is a factor of 10 larger than that predicted from the change in permeability, suggesting that large measurement error in the mass concentration data is a major limitation (POLAK et al., 2004). Alternatively, additional dissolved mass from the sample interior, not contributing to the change in aperture could participate in the process, and result in the observed mismatch. Upon switching the influent fluid to distilled water $(\mathrm{pH} \sim 6)$, the observed change in permeability closely matches the change predicted from the mass efflux. This matches for an unmeasured but reasonable asperity contact area of $25 \%$. Finally, as the aperture closes, and flow is progressively restricted to the continuous path of the largest initial apertures, one single conduit develops as the principal flow path - the observed mass removal rate is consistent with the evolution of a flow path $10 \mathrm{~mm}$ in width. This observation is consistent with the development of the wormhole, apparent in the scanning data of Figure 8. Although only diagnostic, these models 
First scan -0 hours
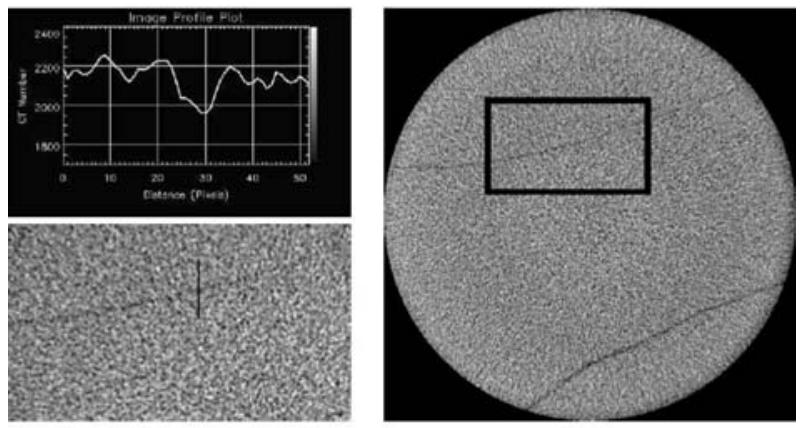

Fourth scan - 1492 hours
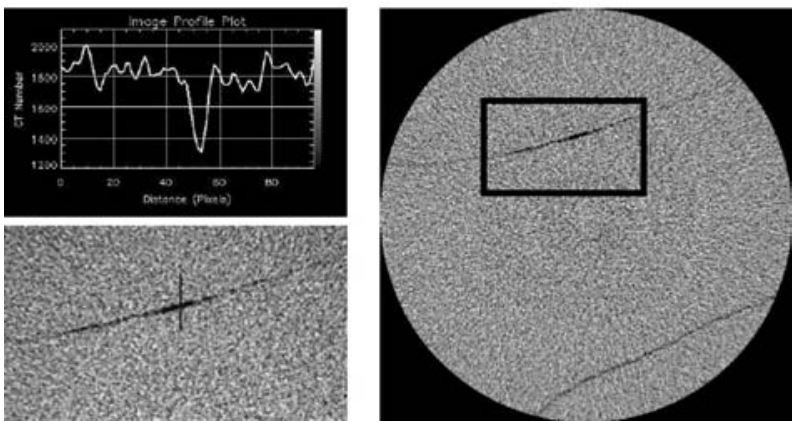

Figure 8

Scan of the fractured limestone sample (above) pre- and (below) post-circulation. Growth of the fracture aperture occurs during the test. Change in CT number across the sample confirms growth of the fracture as a wormhole (POLAK et al., 2004).

are consistent with the findings from prognostic lumped-parameter models that enable this response to be followed a posteriori (YASUHARA et al., 2004) and to match proposed mechanisms with observations.

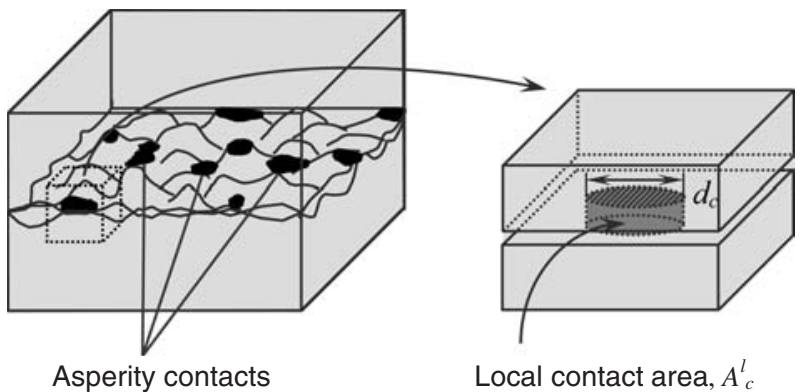

Figure 9

Idealized representation of the asperity contact condition. One representative contact area, $A_{c}^{l}$ (right side), represents the area of each asperity in contact (left side), and is considered circular in shape, of diameter, $d_{c}$. 


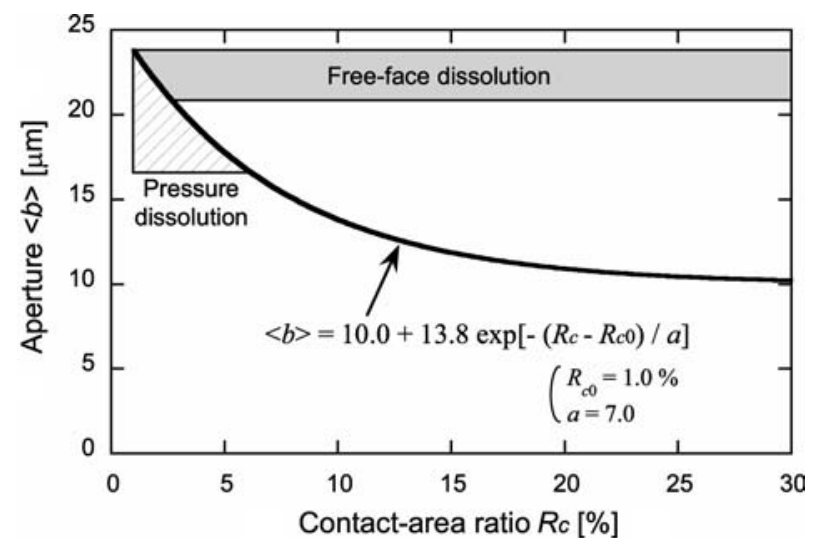

Figure 10

Relationship between aperture and contact area.

\section{Micro-Scale Models-Scaling in Space and in Time}

Clear from the experimental data, is the need to scale response in both space and in time. Fracture closure is clearly time dependent, and asymptotes in time to final closure - this in turn is controlled by the geometry of the asperity arrangement, as will be described here.

A mechanistic model is presented to describe the dissolution-dependent evolution of a fracture aperture in rock that accommodates the competing processes of pressure (dis)solution and free-face dissolution. Fracture aperture (or related permeability) may decrease if pressure solution dominates, or may increase if freeface dissolution prevails. Incorporating the role of pressure solution beneath the bridged contact points of a rough fracture has been shown adequate in replicating the observed closure of a natural fracture in novaculite (YASUHARA et al., 2004). This model follows the three serial processes of interfacial dissolution beneath the contacting asperity indentor, mass diffusion along the indentor-iterface, and subsequent precipitation within the fracture void. This is capable of replicating the observed monotonic closure of the fracture as pressure solution dominates (POLAK et al., 2003). In contrast, where permeability change spontaneously switches from net closure to net gaping, the role of free-face dissolution must be accommodated (PolAK et al., 2004), as this is the presumed mechanism that enables the evolution of a dominant etched flow conduit. This development is detailed in the following.

\subsection{Rates of Pressure Solution and Free-face Dissolution}

The evolution of fracture aperture is controlled by the competing influences of pressure solution and free-face dissolution. Pressure solution within a fracture 
incorporates three serial processes; dissolution at asperity contacts, diffusion along the interfacial water film, and precipitation at the pore wall, and may result in net reduction of fracture aperture. This results if the solubility of the solute is above the equilibrium concentration for the solvent. Conversely, if the mass rate of supply to the fluid occupying the fracture void is sufficiently low, or the flow-system sufficiently open, then the solute concentration in the pore fluid will be below the equilibrium concentration, net dissolution will proceed, and the fracture will widen. The competition between pressure solution and precipitation in the fracture void, that together contribute to a net reduction in permeability, and dissolution from the wall of the fracture void, that will net increase permeability, will prescribe the dominant effect; either net sealing or gaping. Importantly, the dominant mechanism may change with stress and the chemical condition of the solvent, or as a result of the evolution of fracture topography, and flow topology.

First, dissolution at the asperity contacts provides a source of mass into the fracture cavity, and is most conveniently defined in terms of a dissolution mass flux, $d M_{\text {diss }}^{P S} / d t$, given as (YASUHARA et al., 2003),

$$
\frac{d M_{\mathrm{diss}}^{P S}}{d t}=\frac{3 \pi V_{m}^{2}\left(\sigma_{a}-\sigma_{c}\right) k_{+} \rho_{g} d_{c}^{2}}{4 R T}
$$

where $V_{m}$ is molar volume of the solid $\left(3.69 \times 10^{-5} \mathrm{~m}^{3} \mathrm{~mol}^{-1}\right.$ for calcite), $\sigma_{a}$ is the disjoining pressure (e.g., Heidug, 1995) equal to the amount by which the pressure acting at grain-to-grain contacts exceeds the hydrostatic pore pressure, $k_{+}$is the dissolution rate constant of the solid, $\rho_{g}$ is the grain density ( $2710 \mathrm{~kg} \mathrm{~m}^{-3}$ for calcite), $d_{c}$ is the diameter of the asperity contact, $R$ is the gas constant, $T$ is the temperature of the system, and $\sigma_{c}$ is the critical stress, which defines stress state where the compaction of grain aggregate will effectively halt.

Second, based on Fick's first law and integrating it with respect to a circular contact of radius $r$ in the range $a \leq r \leq d_{c} / 2$, diffusion along the asperity contact area is defined in terms of the diffusive mass flux, $d M_{\mathrm{diff}} / d t$, as (YASUHARA et al., 2003),

$$
\frac{d M_{\text {diff }}}{d t}=\frac{2 \pi \omega D_{b}}{\ln \left(\frac{d_{c}}{2 a}\right)}\left(C_{\mathrm{int}}-C_{\text {pore }}\right),
$$

where $\omega$ is the thickness of the water film trapped at the interface, $D_{b}$ is the diffusion coefficient, and $\left(C_{\mathrm{int}}\right)_{x=a}$ and $\left(C_{\mathrm{pore}}\right)_{x=d_{c} / 2}$ are mineral concentrations in the interface fluid and pore space, respectively.

Finally, free-face dissolution/precipitation are quantified as mass fluxes, $d M_{\mathrm{diss}}^{F F} / d t$ and $d M_{\text {prec }} / d t$, defined by the dissolution/precipitation rate constants and difference between the fluid mass concentration in the pore space and the equilibrium concentration, defined as (modified from PALMER, 1991; DreYbrodt and BuHMANN, 1991), 


$$
\begin{aligned}
& \frac{d M_{\mathrm{diss}}^{F F}}{d t}=k_{+} A_{\text {pore }} \rho_{g} V_{m}\left(1-\frac{C_{\mathrm{pore}}}{C_{\mathrm{eq}}}\right)^{n}, \\
& \frac{d M_{\mathrm{prec}}}{d t}=k_{-} A_{\mathrm{pore}} \rho_{g} V_{m}\left(\frac{C_{\mathrm{pore}}}{C_{\mathrm{eq}}}-1\right)^{n},
\end{aligned}
$$

where $A_{\text {pore }}$ is the area of the fracture void, $k_{-}$is the precipitation rate constant of the dissolved mineral, and $C_{\text {eq }}$ is the equilibrium solubility of the dissolved mineral. $n$ denotes the reaction order, which is experimentally constrained (DREYBRODT, 1998): The reaction kinetics is roughly first order for a pore fluid undersaturated with calcium, and the reaction order increases as the water approaches saturation. In this preliminary model, the order is set to unity as a fist approximation. Note that the dissolution/precipitation mass fluxes will be zero as the mass concentration in the pore fluid is either greater or smaller than the equilibrium solubility, respectively.

\subsection{Geometric Effects}

A single fracture is idealized as two rough surfaces held apart by bridging asperities, as illustrated in Fehler! 'Verweisquelle konnte nicht gefunden warden.' (left side) The average contact-area ratio, $R_{c}$, may be determined by defining a representative contact area, $A_{c}^{l}$, surrounded by an appropriate tributary area, $A_{t}^{l}$, '(Fehler! Verweisquelle konnte nicht gefunden warden'.; right side), and is assumed equivalent to the ratio of the summed local contact areas, $A_{c}^{t}$, to the total fracture area, $A_{t}^{t}$, given as (YASUHARA et al., 2004),

$$
R_{c}=\frac{A_{c}^{l}}{A_{t}^{l}}=\frac{A_{c}^{t}}{A_{t}^{t}} .
$$

Within this tributary area, the contact diameter, $d_{c}$, of the local contact area, $A_{c}^{l}$, is defined as,

$$
d_{c}=\sqrt{\frac{4 A_{c}^{l}}{\pi}}
$$

For uniaxial compaction, the normal forces acting on the tributary area and the contacting asperity balance, yielding the stress applied at the contact area, $\sigma_{a}$, as,

$$
\begin{gathered}
\sigma_{\mathrm{eff}} \cdot A_{t}^{l}=\sigma_{a} \cdot A_{c}^{l} \\
\Rightarrow \sigma_{a}=\frac{\sigma_{\mathrm{eff}}}{R_{c}},
\end{gathered}
$$

where $\sigma_{\text {eff }}$ is the average macroscopic effective stress.

Interactive processes of pressure solution and free-face dissolution irreversibly alter the geometry of the fracture surfaces, and the relation between fracture aperture and contact area may be defined to follow this modification of the fracture aperture 
and contact-area ratio within the tributary domain. A simple, but physically viable, relation between them is defined as (YASUHARA et al., 2004),

$$
\langle b\rangle=a_{1}+a_{2} \cdot \exp \left(-\left(R_{c}-R_{c 0}\right) / a_{3}\right),
$$

where $\langle b\rangle$ is the mean aperture, $R_{c}$ is the contact-area ratio, and $a_{i}(i=1,2,3)$ is a constant. This curve is adopted as a straightforward and representative relation between fracture contact area and aperture, to define the phenomenology of fracture sealing/gaping by pressure solution/free-face dissolution.

\subsection{Computational Procedure}

The individual processes of dissolution at asperity contacts, diffusion along interfacial water film, and free-face dissolution/precipitation are combined to define the progress of aperture reduction of the fracture with time. In the initial condition, a small representative contact area is set with the initial aperture of the fracture. An effective stress is applied, as amplified by the tributary geometry, and during time step $\Delta t$, appropriate magnitudes of mass dissolution at the representative contact area, diffusion, and free-face dissolution/precipitation are simultaneously evaluated from Eqs. (1), (2), (3), and (4), respectively. Physically, the dissolved mass evaluated from Eq. (1) is supplied to the interface, and domain shortening (i.e., aperture reduction) proceeds as this mass passes along the interface by diffusion, as defined by Eq. (2). From the known magnitude of the diffusing mass, the updated contact area and aperture are calculated using the relation of Eq. (14) (the integration of Eq. (8) represents the volume that is removed, and its volume is matched by the diffused volume). A portion of the mass that diffuses to the pore fluid may deposit to the free surface of the fracture (Eq. (4)), resulting in an additive reduction in fracture void volume. Alternately, net dissolution from the fracture wall (Eq. (3)) and resulting enlargement of the void cavity will compete with the closure occasioned by the shortening of the bridging asperity. The dominant process will prescribe whether the fracture gapes or seals '(Fehler! Verweisquelle konnte nicht gefunden warden.)'. This deposition or dissolution on the free surface is controlled by the relative concentration differential between the pore fluid solution and the equilibrium concentration of that fluid (Eqs. (3) and (4)). Concurrently, mineral concentrations in the immobile fluid layer beneath the asperity contact, and the mobile fluid in the fracture void fluid are updated, as (YASUHARA et al., 2004),

$$
\left.C_{\text {int }}\right|_{t+\Delta t}=\frac{\left(D_{1}+V_{p} / 2 \Delta t\right) \cdot\left(d M_{\text {diss }} / d t+V_{p} /\left.4 \Delta t \cdot C_{\text {int }}\right|_{t}\right)+D_{1} V_{p} /\left.2 \Delta t \cdot C_{\text {pore }}\right|_{t}}{\left(D_{1}+V_{p} / 4 \Delta t\right) \cdot\left(D_{1}+V_{p} / 2 \Delta t\right)-D_{1}^{2}}
$$

where,

$$
D_{1}=\frac{2 \pi \varpi D_{b}}{\ln \left(d_{c} / 2 a\right)}
$$




$$
\begin{gathered}
C_{\text {pore }}=\frac{1}{Q}\left(\frac{d M_{\text {diff }}}{d t}+\frac{d M_{\text {diss }}^{F F}}{d t}\right) \quad\left(\text { if } \quad C_{\text {pore }}<C_{\mathrm{eq}}\right), \\
C_{\text {pore }}=\frac{1}{Q}\left(\frac{d M_{\text {diff }}}{d t}-\frac{d M_{\text {prec }}}{d t}\right) \quad\left(\text { if } \quad C_{\text {pore }}>C_{\text {eq }}\right),
\end{gathered}
$$

and $Q$ denotes the flow rate.

These relations are used iteratively to follow the evolution of dissolved concentrations within the fracture void, and resulting closure history of the fracture.

\section{Match with Observed Behavior}

The evolution of fracture aperture with the progress of the experiment is represented by the prior model. We follow the measured change in aperture observed in the experiment, from an initial aperture of $24 \mu \mathrm{m}$; first closing, and then spontaneously gaping (PoLAK et al., 2004). Importantly, we provide no ad hoc mechanism to trigger the spontaneous change to gaping; rather this evolves as a natural consequence of the competition between agents that promote either asperity removal, or alternately free-face etching, explicitly represented in the model.

The predicted rates of evolutions in aperture and differential concentration in $\mathrm{Ca}$ (outlet minus inlet) are shown in Figure 11, together with the experimental measurements. This response is derived for the physical parameters identified in Table 2, but modified in magnitude by the scaling parameters previously described.

Stage I Behavior $(p H \sim 8)$ : With the fractional contact area initiated at $1 \%$, the evolving modeled aperture closely matches that evaluated from the flow data. The fracture evolution is insensitive to this choice, and reaches an intermediate contact area of $6 \%$ at the close of stage I (932 hr), corresponding to an aperture of $18 \mu \mathrm{m}$ (Fig. 11(a)). Measured and predicted $\mathrm{Ca}$ concentrations are compared in Figure 11(b). Evaluated concentration changes (outlet minus inlet) are of the order $\sim 0.01 \mathrm{ppm}$, and are absent the broad swings recorded in the experimental measurements (POLAK et al., 2004), attributed to large relative measurement errors, and net dissolution from the matrix, unaccounted in the model. Predicted $\mathrm{Ca}$ concentrations in the pore fluid are slightly larger than the equilibrium solubility, which results in nominal precipitation to the pore wall; the diminution in fracture aperture is less than $\sim 10 \mathrm{~nm}$, and is indiscernible in Fig. 11. Correspondingly, aperture evolution is controlled only by stress-mediated dissolution.

Stage II and III Behavior $(\mathrm{pH} \sim 6)$ : As distilled water is introduced, the fracture closure initially accelerates, and the contact area increases to $\sim 15 \%$ at the minimum aperture of $12 \mu \mathrm{m}(1082 \mathrm{hr})$. The closure accelerates due to the increase in stressmediated dissolution (Eq. (13)) prompted by the lowering of $\mathrm{pH}$ in the influent fluid, 

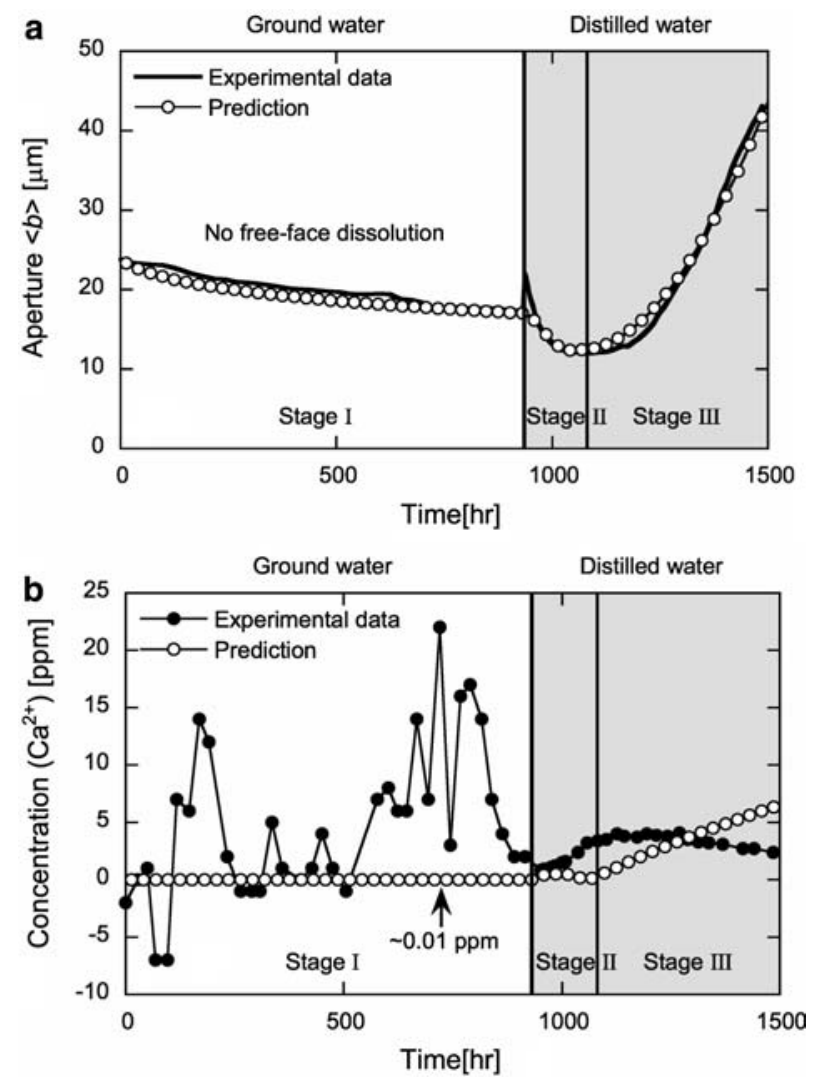

Figure 11

Comparisons between experimental data of POLAK et al. (2004) and predictions of the current model, (a) aperture change with time and (b) change in calcium concentrations (outlet minus inlet) with time. Open circles show the predictions using modified values; with $k_{+}=0.01 \times\left(1.15 \times 10^{-6}\right) \mathrm{mol} \mathrm{m}^{-2} \mathrm{~s}^{-1}$ in stage I; with $k_{+}=2.0 \times\left(1.15 \times 10^{-6}\right) \mathrm{mol} \mathrm{m}^{-2} \mathrm{~s}^{-1}$ in stages II and III, and $A_{\text {pore }}$ is decreased by a factor of $1 /$ 200 in stages I and II and the factors of $A_{\text {pore }}$ are linearly increased from $1 / 200$ to $60 / 200$ in stage III.

Table 2

Parameters used to represent the experimental results

\begin{tabular}{|c|c|c|c|c|c|c|c|}
\hline $\begin{array}{c}\text { Temperature } \\
T\left[{ }^{\circ} \mathrm{C}\right]\end{array}$ & $\begin{array}{c}\text { Effective } \\
\text { stress } \\
\sigma_{\text {eff }}[\mathrm{MPa}]\end{array}$ & $\begin{array}{c}\text { Critical } \\
\text { stress } \\
\sigma_{c}[\mathrm{MPa}]\end{array}$ & $\begin{array}{l}\text { Diffusion } \\
\text { path } \\
\text { Width } \\
\omega[\mathrm{nm}]\end{array}$ & $\begin{array}{l}\text { Diffusion } \\
\text { coefficient } \\
D_{b}\left[\mathrm{~m}^{2} \mathrm{~s}^{-1}\right]\end{array}$ & $\begin{array}{c}\text { Dissolution } \\
\text { rate constant } \\
k_{+}\left[\mathrm{mol} \mathrm{m} \mathrm{m}^{-2} \mathrm{~s}^{-1}\right]\end{array}$ & $\begin{array}{l}\text { Precipitation } \\
\text { rate constant } \\
k_{-}\left[\mathrm{mol} \mathrm{m} \mathrm{m}^{-2} \mathrm{~s}^{-1}\right]\end{array}$ & $\begin{array}{c}\text { Solubility of } \\
\text { calcium } \\
C_{\text {eq }}[\mathrm{ppm}]\end{array}$ \\
\hline 20 & 3.0 & 20.0 & 4.0 & $6.93 \times 10^{-10}$ & $1.15 \times 10^{-6}$ & 1.78 & 37.4 \\
\hline
\end{tabular}

as reflected in the elevated dissolution constant, $k_{+}$. During stage II, stress-mediated dissolution dominates, but this dominance switches to free-face dissolution as the fracture topography and flow topology chang in response to dissolution. This switch 
is marked as the onset of stage III, but importantly, experimental variables are invariant throughout stages II and III. If model parameters are not changed, the fracture slowly gapes as free-face dissolution builds in the constricted void, relative to the effect of stress-mediated dissolution. This spontaneous switching in aperture, and related permeability, evolution is illustrated in Figure 11(a), although the modeled rate of aperture growth in this final stage is muted over observed behavior. The observed rate of aperture growth can only be matched if the surface area is arbitrarily increased over the period 1082 to 1487 hours, to represent the observed localization of mass removal within a restricted conduit. In this instance, the modeled response closely matches the measured growth in effective aperture from $\sim 12$ to $\sim 43 \mu \mathrm{m}$, although the assumed geometry of the fracture remains parallel-sided rather than tubular in section (PoLAK et al., 2004).

Throughout stage II, the contact-area ratio monotonically increases from $\sim 6$ to $\sim 15 \%$, proportionately decreasing the contact stresses, $\sigma_{a}$, and increasing the mass diffusion length. These changes provide a reinforcing feedback in slowing the rate of pressure solution (i.e., aperture reduction), allowing free-face dissolution to dominate, and promote gaping of the fracture. For this sample, this transition occurs at $\sim 1028$ $\mathrm{hr}$, and marks the transition between stages II and III of the experiment.

\section{Conclusions}

The previous has documented the surprising influence that complex paths of temperature and chemical potential may exert on the transport properties of fractured rocks. Pressure solution is shown to be potentially an important factor, which, under certain circumstances may strongly influence response. Pressure solution, representing a mechanism of stress-mediated (enhanced) dissolution, can be mobilized at relatively modest temperatures $\left(\sim 20^{\circ}-80^{\circ} \mathrm{C}\right)$ and stresses $(\sim 3.5 \mathrm{MPa})$, and can act rapidly — on the order of a few to tens of days. These effects are shown to be surprisingly virulent capable of changing permeabilities by many orders of magnitude within these short time frames. Surprisingly, these effects may result in the net reduction of fracture aperture, and consequent reduction in permeability, even when mineral mass is net dissolved and removed from the sample, throughout. Correspondingly, these processes may exert a significant influence on the circulation of fluids in natural and engineered environments, especially those involving significant temporal or spatial gradients in stress, chemical potential, or temperature, and warrant close scrutiny.

\section{Acknowledgements}

This work has been supported by grants DOE-BES-DE-FG02-00ER15111, DOE-DE-PS26-01NT41048, DOE-DE-FG36-04GO14289, and ARC DP0209425. 
This support is gratefully acknowledged. This work would not have been possible without the contributions of Amir Polak, Avrami Grader, Phil Halleck, and Jishan Liu. Mike Howard and Charles Stone (Arkansas Geological Commission) are thanked for providing a bulk sample of Arkansas novaculite. The comments of Sergei Fomin and one anonymous reviewer are appreciated.

\section{REFERENCES}

Aharonov, E., Tenthorey, E., and Scholz, C.H. (1998), Precipitation sealing and diagenesis - 2. Theoretical analysis, J. Geophys. Res.-Solid Earth 103, 23,969-23,981.

Bernabe, Y., MoK, U., and Evans, B. (2003), Permeability-porosity relationships in rocks subjected to various evolution processes, Pure Appl. Geophys. 160, 937-960.

Bos, B., PeAch, C.J., and SpIERs, C.J. (2000), Slip behavior of simulated gouge-bearing faults under conditions favoring pressure solution, J. Geophys Res.-Solid Earth 105, 16,699-16,717.

Colon, C.F.J., OelKers, E.H., and SchotT, J. (2004), Experimental investigation of the effect of dissolution on sandstone permeability, porosity, and reactive surface area, Geochim. et Cosmochim. Acta 68, 805817.

Dreybrodt, W. and Buhmann, D. (1991), A mass transfer model for dissolution and precipitation of calcite from solutions in turbulent motion, Chem. Geol. 90, 107-122.

Dreybrodt, W., Principles of karst evolution from initiation to maturity and their relation to physics and chemistry. In Global Karst Correlation (D.X. Yuan, and Z. H. Liu, eds.) (Science Press, Beijing, (1998)) pp. 33-49.

Durham, W.B., Bourcier, W.L., and Burton, E.A. (2001), Direct observation of reactive flow in a single fracture, Water Resour. Res. 37, 1, 1-12.

Elias, B. P. and Hajash, A. (1992) Changes in Quartz Solubility and Porosity Due to Effective Stress - an Experimental Investigation of Pressure Solution. Geology 20 (5) 451-454.

Evans, J.P., Forster, C.B., and Goddard, J.V. (1997), Permeability of fault-related rocks, and implications for hydraulic structure of fault zones, J. Struct. Geology 19, 1393-1404.

Gratier, J.-P. (1993), Experimental pressure solution of halite by an indenter technique, Geophys. Res. Lett. 20, 1647-1650.

Hajash, A., Carpenter, T.D., and Dewars, T.A. (1998), Dissolution and time-dependent compaction of albite sand: Experiments at $100^{\circ} \mathrm{C}$ and $160^{\circ} \mathrm{C}$ in $\mathrm{pHpH}$-buffered organic acids and distilled water, Tectonophysics 295 (1-2), 93-115.

HEIDUG, W.K. (1995), Intergranular solid-fluid phase transformations under stress: The effect of surface forces, J. Geophys. Res. 100, 5931-5940.

Lin, W., Roberts, J., Glassley, W., and Ruddle, D. (1997), Fracture and matrix permeability at elevated temperatures, Workshop on Significant Issues and Available Data. Near-Field/Altered-Zone Coupled Effects Expert Elicitation Project, San Francisco, November.

Main, I.G., Kwon, O., NGwenya, B.T., and Elphick, S.C. (2000), Fault sealing during deformation-band growth in porous sandstone, Geology 28, 1131-1134.

Mok, U., Bernabe, Y., and Evans, B. (2002), Permeability, porosity and pore geometry of chemically altered porous silica glass, J. Geophys. Res.-Solid Earth 107.

Moore, D.E., Lockner, D.A. et al. (1994), Reduction of Permeability in Granite at Elevated-Temperatures. Science 265 (5178) 1558-1561.

Ngwenya, B.T., Kwon, O., Elphick, S.C., and Main, I.G. (2003), Permeability evolution during progressive development of deformation bands in porous sandstones, J. Geophys. Res.-Solid Earth 108.

Palmer, A.N. (1991), Origin and morphology of limestone caves, Geol. Soc. Am. Bull. 103, 1-21.

Piggott, A.R. and Elsworth, D. (1993), Laboratory assessment of the equivalent apertures of a rock fracture, Geophys. Res. Lett. 20 (13), 1387-1390. 
Polak, A., Elsworth, D., Yasuhara, H., Grader, A.S., and Halleck, P.M. (2003), Permeability reduction of a natural fracture under net dissolution by hydrothermal fluids, Geophys. Res. Lett. 30 (20), 2020, doi:10.1029/2003GL017575.

Polak, A., Elsworth, D., Liu, J., and Grader, A. (2004), Spontaneous switching of permeability changes in a limestone fracture under net dissolution, Water. Resour. Res. 40, W03502, doi:10.1029/ 2003WR002717.

Siddiqi, G., Evans, B., Dresen, G., and Freund, D. (1997), Effect of semibrittle deformation on transport properties of calcite rocks, J. Geophys. Res. 102 (B7), 14,765-14,778.

Tenthorey, E., Scholz, C.H., Aharonov, E., and Leger, A. (1998), Precipitation sealing and diagenesis - 1. Experimental results, J. Geophys. Res.-Solid Earth 103, 23,951-23,967.

Yasuhara, H., Elsworth, D., and Polak, A. (2003), A mechanistic model for compaction of granular aggregates moderated by pressure solution, J. Geophys. Res. 108 (B11), 2530, doi:10.1029/2003JB002536.

Yasuhara, H., Elsworth, D., and POLAK, A. (2004), The evolution of permeability in a natural fracture: Significant role of pressure solution, J. Geophys. Res. 109, B03204, doi:10.1029/2003JB002663.

Zhang, S., Cox, S., and Paterson, M. (1994), The influence of room temperature deformation on on porosity and permeability in calcite aggregates, J. Geophys. Res. 99, 15,761-15,775.

Zhang, S.Q., Tullis, T.E., and Scruggs, V.J. (1999), Permeability anisotropy and pressure dependency of permeability in experimentally sheared gouge materials, J. Struct. Geol. 21, 7, 795-806.

ZHu, W.L. and Wong, T.F. (1997), The transition from brittle faulting to cataclastic flow: permeability evolution, J. Geophys. Res. 102, B2, 3027-3041.

Zoback, M. and Byerlee, J. (1975), The effect of microcrack dilatancy on the permeability of Westerly Granite J. Geophys. Res. 80, 752-755.

(Received February 24, 2005, revised October 28, 2005, accepted November 10, 2005)

To access this journal online:
http://www.birkhauser.ch

